\title{
¿Un estatuto básico para los municipios pequeños?: Un comentario de urgencia $^{1}$
}

\section{A basic statute for the small municipalities?: An urgent comment}

\author{
Eloísa Carbonell Porras \\ Universidad de Jaén (España) \\ ORCID: https://orcid.org/0000-0003-1127-1730 \\ eloisa.carbonell@ujaen.es
}

\begin{abstract}
NOTA BIOGRÁFICA
Catedrática de Derecho Administrativo en la Universidad de Jaén. Sus principales líneas de investigación se centran en el Derecho de la Organización en general y el Derecho local y los órganos colegiados en particular, así como en el Derecho Público del transporte y la movilidad, además de otros temas como los relativos a la legitimación y los intereses colectivos o la economía colaborativa.
\end{abstract}

\section{RESUMEN}

Desde el verano de 2020, han sido frecuentes las noticias relativas a la intención del Gobierno de adicionar un nuevo título a la legislación básica de régimen local, que estaría dedicado a los municipios pequeños. Este Estatuto Básico para los Municipios de Menor Población se ha vinculado además con el denominado reto demográfico. Se delimita así el objeto de este trabajo, centrado en el estudio del régimen actual de estos municipios, el carácter rural de muchos de ellos y reflexionar sobre el contenido que podría tener el Estatuto Básico y su relación con los problemas demográficos.

\section{PALABRAS CLAVE}

Régimen local; municipios pequeños; ámbito rural; planta municipal; despoblación.

\begin{abstract}
Since summer 2020 it have been frequently news concernig the Government's intention to add a new title to the basic legislation of local government, wich it would be dedicated to small municipalities. This Basic Statute for the Small Municipalities has also been linked to the so-called demographic challenge. The aim of this work is based on the study of the current legal regimen on theses municipalities, the rural character of many of them, and thinking about the content that the Basic Statute could have and its relation with demografic problems.
\end{abstract}

\section{KEYWORDS}

Local government; small municipalities; rural character; municipal structure; depopulation.

1 Este trabajo ha sido realizado en el marco del Proyecto I+D+i del Plan Nacional, "Las Entidades locales, sus relaciones y competencias. Realidad, efectos y consecuencias de la racionalización y sostenibilidad financiera en clave nacional y europea" (DER201674843-C3-1-R), del que soy Investigadora principal, y de la Estructura de Investigación de la Universidad de Jaén SEJ 09, integrados ambos en el Grupo de Investigación de la Junta de Andalucía, "Administración Pública y Ciudadanos: régimen jurídico", (APCI), PAIDI SEJ-630, que dirijo en la Universidad de Jaén. También responde a la Red Temática, acción de dinamización del Plan Nacional, que coordino sobre "Gobiernos locales y economía colaborativa" (GOBECOL), (RED2018-102319-T). 
REALA. Nueva Época - N. ${ }^{15}$, abril 2021 - ISSN: 1989-8975 - DOI: https://doi.org/10.24965/reala.i15.10922 - [Págs. 58-70]

¿Un estatuto básico para los municipios pequeños?: Un comentario de urgencia

Eloísa Carbonell Porras

\begin{abstract}
SUMARIO
1. EL PROBLEMA DEMOGRÁFICO Y EL ANUNCIADO ESTATUTO BÁSICO DE LOS PEQUEÑOS MUNICIPIOS: BREVE COMENTARIO DE URGENCIA. 2. DESPOBLACIÓN, MUNICIPIOS PEQUEÑOS Y DE ÁMBITO RURAL: REALIDADES DIFERENTES, AUNQUE RELACIONADAS. 3. RÉGIMEN JURÍDICO DE LOS MUNICIPIOS PEQUEÑOS: PRINCIPALES CARACTERES Y PARTICULARIDADES. 4. ¿UN ESTATUTO BÁSICO PARA LOS MUNICIPIOS PEQUEÑOS PARA HACER FRENTE AL PROBLEMA DEMOGRÁFICO? 5. REFLEXIÓN FINAL. 6. REFERENCIAS BIBLIOGRÁFICAS Y DOCUMENTOS.
\end{abstract}

\title{
1. EL PROBLEMA DEMOGRÁFICO Y EL ANUNCIADO ESTATUTO BÁSICO DE LOS PEQUEÑOS MUNICIPIOS: BREVE COMENTARIO DE URGENCIA
}

El verano pasado el Gobierno anunció su intención de reformar la legislación estatal básica de régimen local para avanzar en la autonomía local y, entre otras cosas, elaborar un Estatuto Básico para los Pequeños Municipios, novedad que se enmarcaría en la Estrategia Nacional frente al Reto Democrático. Este anuncio provocó una especial atención en los medios de comunicación social con numerosas referencias a este Estatuto, que renovaría los municipios más pequeños para adecuarlos a la realidad socio-económica y enfrentarse más adecuadamente al reto demográfico. Al respecto hay que tener en cuenta que el desplazamiento de la población a las grandes ciudades con la consiguiente despoblación de la España rural comenzó hace más de medio siglo, aunque en los últimos tiempos ha cobrado visibilidad en lo que se ha dado en llamar la España vaciada. Entre 2011 y 2019 se ha experimentado un crecimiento demográfico global cercano al $15 \%$ (el país pasa de 41,1 a 47,4 millones de habitantes), pero en cuatro Comunidades Autónomas (Extremadura, Galicia, Castilla y León y Asturias) se ha intensificado la pérdida de población que venían sufriendo, y cinco más (Aragón, Cantabria, Castilla-La Mancha, Comunidad Valenciana y La Rioja) se han sumado a esta tendencia. Con estos datos, se explica la preocupación por este problema que, además, es compartido por otros países de la Unión Europea. Prueba de ello es la referencia que, en el marco de la cohesión económica, social y territorial, realiza el artículo 174 del Tratado de Funcionamiento de la Unión Europea a las zonas rurales y a las regiones que padecen desventajas naturales o demográficas graves y permanentes, como las regiones más septentrionales con una escasa densidad de población y las regiones insulares, transfronterizas y de montaña ${ }^{2}$. En España, la importancia política de esta cuestión se ha potenciado en los últimos años ${ }^{3}$. Así, en la VI Conferencia de Presidentes de Comunidades Autónomas, celebrada el 17 de enero de 2017, se defendió la necesidad de elaborar y desarrollar una estrategia nacional para intentar dar respuesta a los problemas demográficos, especialmente al progresivo envejecimiento de la población, al despoblamiento territorial y a los efectos de la población flotante. Para ello, se creó el Comisionado del Gobierno frente al Reto Demográfico (Real Decreto 40/2017, de 27 de enero), que ha elaborado las Directrices Generales de la Estrategia Nacional Frente al Reto Demográfico, aprobadas por el Consejo de Ministros el 29 de marzo de 2019. En 2020 se refuerza la relevancia política de este tema con la creación del Ministerio para la Transición Ecológica y el Reto Demográfico (Real Decreto 2/2020, de 12 de enero), de la Comisión Delegada del Gobierno para el Reto Demográfico (Real Decreto 399/2020, de 25 de febrero) y de la Conferencia Sectorial de Reto Demográfico ${ }^{4}$. En este contexto, el Plan Normativo 2020, aprobado por el Consejo de Ministros el 8 de septiembre, prevé la modificación de Ley 7/1985, de 2 de abril, reguladora de las Bases del Régimen Local (en adelante, LBRL) para la recuperación de la autonomía local con un doble objetivo: por un lado, «para el diseño de políticas públicas y reforma de cuestiones puntuales relativas al procedi-

2 En esta línea puede verse el Informe sobre el impacto del cambio demográfico de la Comisión, de 17 de junio de 2020 , y el Dictamen del Comité Europeo de las Regiones, La respuesta de la UE al reto demográfico, (2017/C 017/08) (Diario Oficial de la Unión Europea, C17/40, de 18 de enero de 2017), con ponencia del Presidente de la Junta de Castilla-La Mancha. Además, el programa Horizonte 2020 incluye entre sus retos sociales el cambio demográfico (http://eshorizonte2020.cdti.es/index.asp?MP= 87\&MS=715\&MN=1).

3 Hay que destacar el papel de las Cortes Generales al respecto como refleja el Informe de la Ponencia de estudio para la adopción de medidas en relación con la despoblación rural en la Comisión de Entidades Local en 2015 (Boletín Oficial Cortes Generales. Senado, X Legislatura, núm. 505, de 17 de abril de 2015); y el Informe de 22 de febrero de 2019, de la Comisión Especial de estudio sobre la evolución demográfica y sus consecuencias en España, (Boletín Oficial Cortes Generales. Senado, XII Legislatura, núm. 360, de 1 de abril de 2019), Comisión que se había creado por acuerdo del Pleno de 30 de noviembre de 2016.

4 La aprobación del Real Decreto 500/2020, de 28 de abril de 2020, que desarrolla la estructura orgánica básica del Ministerio para la Transición Ecológica y el Reto Demográfico supondrá la supresión del Comisionado del Gobierno para el Reto Demográfico. El 23 de julio de 2020 se constituye la Conferencia Sectorial de Reto Demográfico, como órgano de cooperación entre la Administración General del Estado y las Administraciones de las Comunidades y Ciudades Autónomas. 
miento de elaboración de normas locales y al ejercicio de la función representativa de los cargos electos»; por otro lado, «con la finalidad de establecer un Estatuto Básico de Pequeños Municipios para conseguir fijar la población al territorio, mantener la calidad democrática del municipio, cumpliendo así con la cláusula del Estado democrático, y garantizar las condiciones de vida de los ciudadanos con independencia del territorio en el que residan, a través de la prestación de unos servicios públicos de calidad ${ }^{5}$. Es esta vinculación entre un nuevo régimen jurídico básico para los municipios pequeños con tan amplios y genéricos objetivos la que motiva este breve comentario. Para ello, a continuación, se alude genéricamente a la despoblación y el carácter rural de muchos municipios con escasa población y al régimen jurídico vigente de los municipios más pequeños. Sobre lo anterior se realizan unas consideraciones generales sobre esta relación entre un nuevo Estatuto Básico de los Municipios Pequeños y el denominado reto demográfico. En todo caso, téngase en cuenta desde ya que no existe una concreta propuesta de reforma y, por tanto, no encontrará el lector en las líneas que siguen un análisis de lo que no existe: sólo se reflexiona sobre la pretendida vinculación entre una reforma del régimen jurídico básico de los municipios con menor población, si es que llega a aprobarse, y los problemas demográficos.

\section{DESPOBLACIÓN, MUNICIPIOS PEQUEÑOS Y DE ÁMBITO RURAL: REALIDADES DIFERENTES AUNQUE REALACIONADAS}

En la recogida de datos sobre la despoblación en España se toma como referencia el municipio pues, como es sabido, el Padrón Municipal de Habitantes es el registro que emplea el Instituto Nacional de Estadística (INE) para la formación de los censos de población, asumiendo también las funciones de supervisión y coordinación de la gestión municipal del Padrón. Por ello, los datos que se emplean para evidenciar el problema demográfico parten de la población municipal: hay 6815 municipios con menos de 5000 habitantes que concentran a 5,7 millones de personas (el $12 \%$ de la población); 5007 tienen una población inferior a 1000 habitantes; y existen 1400 municipios con menos de 100 residentes. El 20,1\% de la población vive en municipios menores de 10000 habitantes, correspondiendo los porcentajes más elevados a Extremadura $(50,2 \%)$, Castilla-La Mancha $(43,7 \%)$ y Castilla y León $(43,3 \%)$, y los más bajos a la Región de Murcia $(3,8 \%)$ y la Comunidad de Madrid (5,6\%). En la última década ocho de cada diez de estos municipios han perdido hasta 410000 habitantes, pérdida de población que también se produce en los municipios de menos de 1000 habitantes (en los que aún viven 1,4 millones de habitantes). Pero la despoblación también afecta a las pequeñas ciudades y capitales de interior: 29 capitales de provincia han perdido población en la última década. Por otra parte, en las dificultades para la prestación de los servicios básicos a los ciudadanos hay que valorar, además del tamaño del municipio, otros factores, como son la dispersión territorial, con numerosos núcleos de población separados, que podrán ser municipios, entidades inframunicipales o carecer de un reconocimiento jurídico; la baja densidad de población, con 3926 municipios con una densidad inferior a los 12,5 habitantes por $\mathrm{km}^{2}$, que es el umbral que la Unión Europea considera como de riesgo demográfico; o el progresivo envejecimiento pues, siendo el país de la Unión Europea con mayor esperanza de vida (82,2 años), hay casi 9 millones de mayores de 65 años que previsiblemente serán más de 15,5 millones en 2050 . Este envejecimiento se concentra en los pequeños municipios rurales: en los de menos de 5000 habitantes, una de cada cuatro personas supera los 65 años, y en los de menos de 1000 habitantes, casi el $15 \%$ de la población alcanza los 80 años. Pero tampoco es un problema privativo de los municipios rurales, y en las grandes ciudades cada vez serán más las personas que superen los 65 años, que en la actualidad son el $19,4 \%$ de la población nacional ${ }^{6}$.

Por último, debe tenerse en cuenta que existen una enorme desigualdad entre Comunidades Autónomas, pues no todas tienen un nivel importante de municipios pequeños. Según los datos del INE a enero de 2020, las Comunidades Autónomas con mayor número de municipios con menos de 5000 habitantes son Castilla y León (2188), Castilla-La Mancha (845), Cataluña (736) y Aragón (707). En Andalucía, la Comunidad Autónoma con mayor población de España (8460000 habitantes) en una extensión de 87581,13 km², existen 785, 529 con población inferior a los 5000 habitantes, pero sólo dos con menos de 100 habitantes (Benitagla, en la provincia de Almería, con 58 y Cumbres de Enmedio, en la de Huelva, con 51). En contras-

5 https://transparencia.gob.es/transparencia/transparencia_Home/index/PublicidadActiva/Normativa/PlanAnualNormativo.html

6 Como señala Díez Sastre, S. (2019, p. 129), el envejecimiento de la población supondrá un reto para la prestación de servicios en el entorno rural y en el urbano, pero también puede plantear problemas de gobernabilidad en los municipios con inferior población. 
te, la Comunidad de Castilla y León, con una extensión algo superior a la andaluza $\left(94224 \mathrm{~km}^{2}\right)$ pero una población sensiblemente inferior (2393000 habitantes), cuenta con 2248 municipios, de los cuales 2188 no alcanzan los 5000 vecinos, y 722 no llegan a los 100. O, por referir una comunidad uniprovincial, La Rioja, que además es la menos poblada (320000 habitantes en $\left.5045 \mathrm{~km}^{2}\right)$, en la que existen 174 municipios, de los cuales 165 no llegan a los 5000 vecinos, y 63 cuentan con menos de 100 residentes $^{7}$.

Estos mismos datos, que relacionan el municipios con su población, son utilizados en las propuestas de reforma del mapa municipal que generalmente abogan por la supresión de los municipios más pequeños por cualquiera de los procedimientos posibles (fusión o agregación especialmente) hasta alcanzar una población de 5000 habitantes al menos, que marcaría la línea de viabilidad comúnmente aceptada ${ }^{8}$. Puede, por tanto, coincidirse en que los municipios pequeños son aquellos que no alcanzan esa cifra de población que, además, es la que tiene en cuenta nuestro Derecho Local en diferentes cuestiones como se comprobará. En esta línea, el artículo 13 LBRL condiciona la creación de nuevos municipios a la existencia de un núcleo de población diferenciado que alcancen al menos los 5000 habitantes $^{9}$. En todo caso, debe tenerse muy presente que estos municipios presentan realidades sustancialmente diferentes teniendo en cuenta la población, la actividad económica predominante, la ubicación... Es evidente que no es lo mismo el de menos de 100 habitantes que el que se aproxima a los 5000 10; ni el de alta montaña, el costero, el histórico, el distante de una gran ciudad o el situado en un entorno metropolitano; tampoco puede equiparse el que tiene como principal actividad económica el sector primario, con el sector secundario o terciario...y todas estas variantes son susceptibles de combinación: un municipio de alta montaña puede dedicarse a la agricultura o a la ganadería o contar con una estación de invierno como principal actividad económica; el costero puede vivir de la pesca o del turismo, actividad económica también presente en municipios pequeños en entornos naturales sobresalientes, o que cuentan con un notable patrimonio histórico-artístico. Asumiendo esta heterogeneidad, y la diversidad de problemas y soluciones que existen, puede aceptarse, a efectos didácticos, que los municipios pequeños serían los que no alcanzan los 5000 vecinos.

La despoblación tiene especial incidencia en el entorno rural, al desplazarse la población a los centros urbanos y costeros. En ese contexto, es fundamental la Ley 45/2007, de 13 diciembre, de desarrollo sostenible del medio rural, que subraya que «toda política rural debe buscar el logro de una mayor integración territorial de las zonas rurales, facilitando una relación de complementariedad entre el medio rural y el urbano, y fomentando en el medio rural un desarrollo sostenible». Esta Ley define el medio rural como el espacio geográfico formado por la agregación de municipios o entidades inframunicipales con una población inferior a 30000 habitantes y una densidad inferior a los 100 habitantes $\mathrm{km}^{2}$; y el municipio rural de pequeño tamaño, como el que posee una población residente inferior a los 5000 habitantes y se integra en el medio rural. El instrumento fundamental para implantar la política rural es el Programa de Desarrollo Rural Sostenible, que se aplica por zonas rurales. Corresponde a las Comunidades Autónomas delimitar las zonas rurales de su territorio y diferenciarlas en tres categorías: las que necesitan revitalización, las intermedias y las periurbanas ${ }^{11}$. Sin perjuicio

7 Estos datos se extraen de la nota de prensa del INE con el avance de la Estadística del Padrón Continuo a 1 de enero de 2020 Como en este avance sólo se alude a los cambios en el último año, también se ha tenido en cuenta el documento El reto demográfico y la despoblación en España en Cifras, 2020, de la Secretaría General para el Reto Demográfico, que se refiere a la última década. Un análisis más detenido de la evolución demográfica en España entre 2015 y 2016 con apoyo en los datos de población de municipios publicados por el INE, puede verse en el documento de trabajo de la Comisión de Despoblación constituida en 2016 en la FEMP, Población y despoblación en España 2016, enero de 2017. En todo caso, téngase en cuenta que en los datos pueden apreciarse variaciones mínimas en función de la fecha que se tome como referencia y que se utilicen los del INE o los de los Registros de entidades locales.

8 Puede verse, entre otros, Cosculluela Montaner, L. (2013, p. 11 y ss.); y Cosculluela Montaner, L. (2017, pp. 239-240). También La planta del Gobierno Local. Actas del VIII Congreso de la Asociación Española de Profesores de Derecho Administrativo, (2013) o el Documento técnico. Elementos para un debate sobre la Reforma Institucional de la Planta Local en el Estado Autonómico, (2012).

9 La exigencia de este mínimo de población trae causa de la modificación de la LBRL operada por la Ley 27/2013, de 27 diciembre, de la racionalización y sostenibilidad de la Administración Local (en adelante, LRSAL), que, en este punto, sí ha sido considerada conforme a la Constitución por el Tribunal Constitucional (SSTC 41/2016 y 108/2017). También deberá acreditarse el cumplimiento de otros requisitos que aseguren la viabilidad del nuevo municipio, que deberá contar los recursos suficientes para prestar sus competencias, pero no son de tan fácil comprobación como los datos de población que ofrece el Padrón Municipal de Habitantes. Al respecto, Carbonell Porras, E. (2019, pp. 31 y ss.) y Pizarro Nevado, R. (2019, pp. 299 y ss.). También, entre otros, Pons Portella, M. (2016, pp. 113-114); Pizarro Nevado, R. (2017, p. 50 y ss.); y Carbonell Porras, E. (2018, pp. 9-10).

10 Según los datos estadísticos del Ministerio de Política Territorial de 2020, hay 1074 municipios con menos de 100 habitantes; 1553, con población entre 100 y 250; 2236 en el tramo entre 251 y 1000 residentes; 928 entre 1001 y 200 habitantes y 1019 entre 2001 y 5000 residentes.

11 De acuerdo con el artículo 10 de la Ley, las zonas rurales a revitalizar son aquéllas con escasa densidad de población, elevada significación de la actividad agraria, bajos niveles de renta y un importante aislamiento geográfico o dificultades de vertebración territorial; las zonas rurales intermedias son aquéllas de baja o media densidad de población, con un empleo diversificado entre el 
de volver sobre esta cuestión con posterioridad, interesa ya subrayar que, para la Ley 45/2007, lo relevante en la existencia de un determinado espacio territorial con unas determinadas características poblacionales generales, no superar los 30000 habitantes y una densidad inferior a los $100 \mathrm{~km}^{2}$, pero el dato de la población del municipio es secundario, integrando también a los que cuentan con población muy superior a los 5000 habitantes, como el hecho de que se trate de un municipio o una entidad local menor ${ }^{12}$. Otra cosa es que los municipios pequeños sean los principales destinatarios de las ayudas destinadas a combatir el problema demográfico en concretos ámbitos materiales de la acción pública.

En efecto, si tenemos en cuenta las acciones generales para el desarrollo rural sostenible y las medidas para su consecución en la Ley 45/2007 y en el Programa de Desarrollo Rural Sostenible se comprueba que son amplias y variadas, mayoritariamente referidas a materias de competencia del Estado y de las Comunidades Autónomas (agricultura, medio ambiente, empleo, infraestructuras, tecnologías de la información y comunicación, energías renovables, agua, seguridad ciudadana, educación, cultura, sanidad, protección social...). Y sólo en casos puntuales se hace referencia a servicios de competencia municipal ${ }^{13}$, generalmente para hacer referencia a la coordinación, la colaboración y la cooperación interadministrativa ${ }^{14}$. Quizá por esto la presencia de representantes de las Entidades locales en los órganos que creó esta Ley se reduce a dos vocales designados por la Federación Española de Municipios y Provincias (FEMP) en el Consejo para el Medio Rural, que es el órgano de coordinación y cooperación entre las distintas Administraciones públicas ${ }^{15}$. Esta relación entre la lucha contra el problema demográfico y el ruralismo con las competencias estatales y autonómicas se mantiene en la actualidad: así, las medidas para luchar contra la despoblación propuestas por la FEMP se ordenan en siete áreas principales (medidas institucionales y modelo territorial; economía y empleo; servicios públicos; infraestructuras, comunicaciones y transporte; vivienda; cultura, identidad y comunicación; e incentivos demográficos) pero no se incluye ninguna concreta propuesta de modificación de la legislación de régimen local ${ }^{16}$. La misma conclusión se extrae de las Directrices Generales de la Estrategia para el Reto Demográfico de 2019. En estos documentos únicamente se insiste en la necesidad de reforzar el papel de las Entidades locales, y particularmente la asistencia y cooperación de las Diputaciones provinciales. Pero ya sabemos que nada de esto es nuevo. Solamente en las medidas frente al reto demográfico del Plan de Recuperación, Transformación y Resilencia, aprobadas por el Ministerio para la Transición Ecológica y el Reto Demográfico en marzo de 2021, se incluye una genérica referencia al Estatuto Básico de los Pequeños Municipios en línea con lo previsto en el Plan Normativo 202017. Tampoco en la legislación

sector primario, secundario y terciario, bajos o medios niveles de renta y distantes del área directa de influencia de los grandes núcleos urbanos; y las zonas rurales periurbanas las de población creciente, con predominio del empleo en el sector terciario, niveles medios o altos de renta y situadas en el entorno de las áreas urbanas o áreas densamente pobladas. Sobre la Ley 45/2007, puede verse GarcíaMoreno Rodríguez, F. (2019) y Fernando Pablo, M. M. et al. (2020); y, desde la perspectiva de género, es imprescindible, González Bustos, M. Á. (2020, p. 75 y ss).

12 Según el primer Programa de Desarrollo Rural Sostenible para el período 2010-2014, aprobado por Real Decreto núm. 752/2010, de 4 de junio, se han incluido 219 zonas rurales, que ocupan una superficie total de $426071 \mathrm{~km}^{2},(\mathrm{el} 84,41 \%$ de la superficie nacional) y poseen una población de 10579281 habitantes (el 22,92\% de la población española). En algunos casos las zonas rurales comprenden la práctica totalidad de la Comunidad Autónoma, y son frecuentes las que superan los 30000 habitantes inicialmente previstos. Al respecto puede verse el capítulo 4 del Programa, que describe las zonas rurales calificando cada una de ellas y especificando la población, la superficie, los municipios y entidades locales menores que comprende. Por ejemplo, puede traerse a colación la zona rural a revitalizar de primer nivel, Lugo Central, con 104198 habitantes y una superficie de 4110,17 km²; la zona rural intermedia, Condado-Guadiodiel, en la provincia de Huelva, con 260220 habitantes y una superficie de 3692,77 km²; o la zona rural periurbana, Mallorca, con 328420 habitantes y una superficie de $3478,85 \mathrm{~km}^{2}$.

13 Como la implantación y ejecución de planes de gestión integral de recursos hídricos por zonas rurales o mancomunidades de municipios (art. 25), de servicios mancomunados o por zona rural de recogida selectiva de residuos y su gestión y el apoyo a la dotación de los servicios públicos municipales de prestación obligatoria en los núcleos urbanos del medio rural, su mantenimiento y mejora, singularmente en las zonas rurales prioritarias, favoreciendo específicamente la prestación coordinada de servicios públicos entre municipios cercanos (art. 23); o la potenciación de programas de servicios sociales por las diversas entidades supramunicipales (art. 32), todos de la Ley $45 / 2007$.

14 Sobre la coordinación como competencia, y los principios de colaboración y cooperación entre Administración públicas, puede verse Rebollo Puig, M. (2019, pp. 313-318 y 380-382).

15 Artículo 7 del Real Decreto 865/2008, de 23 de mayo, por el que se regula la composición, funciones y funcionamiento de la Comisión Interministerial para el Medio Rural, del Consejo para el Medio Rural y de la Mesa de Asociaciones de Desarrollo Rural.

16 Documento de acción de la Comisión de Despoblación de la FEMP con el listado de medidas para luchar contra la despoblación en España, abril 2017. También puede verse la declaración aprobada por el XII Pleno de la FEMP, celebrado en octubre de 2019, Los Gobiernos locales contra la despoblación.

17 El Ministerio propone 130 medidas ordenadas en 10 ejes de acción: Eje 1. Impulso de la Transición Ecológica; Eje 2. Transición Digital y Plena Conectividad Territorial; Eje 3. Desarrollo e Innovación en el Territorio; Eje 4. Impulso del Turismo Sostenible; Eje 5. Igualdad de Derechos y Oportunidades de las Mujeres y los Jóvenes; Eje 6. Fomento del Emprendimiento y de la Actividad Empresarial; 
autonómica vinculada con el desarrollo rural y la despoblación, como la reciente Ley 5/2021, de 2 de febrero, de impulso demográfico de Galicia, se contemplan reformas en el régimen jurídico de los municipios.

De acuerdo con lo anterior que muchos de los municipios más pequeños también sean rurales no significa que todos lo sean: existen municipios con población inferior a 5000 habitantes en nuestras costas, que son municipios turísticos con los problemas singulares que esto implica; en aglomeraciones urbanas, confundiéndose con otros municipios incluso de gran población; en zonas de montaña con una importante estación de invierno.... Siendo esto así, los problemas de estos municipios también presentan sustanciales diferencias que no siempre están vinculados con la despoblación o el ruralismo. Seguidamente se analiza el régimen jurídico básico de los municipios pequeños, que no tiene en cuenta la actividad económica principal, o las dificultades que pueden existir en cada municipio, pequeño o no, por su carácter rural o urbano, turístico, costero, industrial, histórico, de alta montaña...

\section{RÉGIMEN JURÍDICO DE LOS MUNICIPIOS PEQUEÑOS: PRINCIPALES CARACTERES Y PARTICULARIDADES}

Algunos de los municipios más pequeños funcionan en régimen de Concejo Abierto (art. 29 LBRL) y los de menos de 5000 habitantes que se constituyen en Ayuntamientos tienen una organización mínima en la legislación básica del Estado: el Alcalde, los Tenientes de Alcalde y el Pleno (art. 20 LBRL) ${ }^{18}$. El Pleno está integrado por tres concejales (los de menos de 100 residentes), cinco (los de entre 101 a 250 residentes), siete (los de entre 251 a 1000 residentes), nueve (los de entre 1001 a 2000 residentes) y once (los de entre 2001 a 5000 residentes) según dispone el artículo 179 de la LOREG ${ }^{19}$; celebra una sesión obligatoria como mínimo cada tres meses (art. 46 LBRL) y deberá contar con la Comisión Especial de Cuentas (art. 116 LBRL). Los cargos con dedicación exclusiva (que no existirán en los de menos de 1000 habitantes) podrán ser uno en los de población comprendida entre 1001 y 2000 habitantes, dos en los de entre 2001 y 3000 habitantes, y hasta tres en los de población entre 3001 y 10000 habitantes, que podrán percibir una retribución equivalente al $-60 \%$ de un Secretario de Estado (arts. 75 bis y ter LBRL).

En relación con las competencias, el artículo 25 de la LBRL enumera las materias de competencia propia de los municipios sin diferenciar en atención a la población y, consecuentemente, también los pequeños las ostentan, sin perjuicio de lo que pueda establecer la Ley sectorial que las concrete. También los municipios pequeños están amparados por la libertad plena para ejercer su iniciativa en toda materia que no esté excluida de su competencia o atribuida a otra autoridad dentro del ámbito de la Ley como proclama el artículo 4.2 de la Carta Europea de Autonomía Local ${ }^{20}$. Los municipios de menos de 5000 habitantes sólo están obligados a prestar los servicios obligatorios mínimos, que son exigibles en todos ellos con independencia de su población: alumbrado público, cementerio, recogida de residuos, limpieza viaria, abastecimiento do-

Eje 7. Refuerzo de los Servicios Públicos e Impulso de la Descentralización; Eje 8. Bienestar Social y Economía de los Cuidados; Eje 9. Promoción de la Cultura; y Eje 10. Reformas Normativas e Institucionales para abordar el Reto Demográfico. En este último se hace referencia a la redacción del Estatuto básico de los pequeños municipios, por los Ministerios de Política Territorial y Función Pública y para la Transición Ecológica y el Reto Demográfico, que tendría los objetivos que ya conocemos: - Contribuir a la fijación de la población en el territorio, a fin de frenar el vaciamiento de la España interior; - Establecer mecanismos que garanticen el funcionamiento democrático de sus instituciones de gobierno, para la realización efectiva del Estado democrático; - Favorecer una prestación de los servicios públicos locales en términos tales que aseguren una adecuada calidad de vida de los ciudadanos con independencia de su lugar de residencia, a fin de garantizar así la realización efectiva del Estado social.

18 El régimen del Concejo Abierto resultaba obligatorio para los municipios con población inferior a los 100 habitantes (véase Cosculluela Montaner, L.,1987, p. 199 y ss.) hasta que, la Ley Orgánica 2/2011, de 28 de enero, modificó los artículos 29 de la LBRL y 179 de la LOREG, para permitir que los municipios con menos de 100 habitantes se constituyan en Ayuntamientos con plenos integrados por tres concejales. De esta forma, el legislador estatal condicionaba la aplicación de las medidas autonómicas destinadas a eliminar estos municipios pequeños mediante la integración en alguno de los colindantes, reflejando una vez más la ausencia de un criterio claro para corregir el mapa municipal como señalé en Carbonell Porras, E. (2013, p. 40).

19 La elección se rige por el sistema mayoritario en los municipios de menos de 250 habitantes y por el sistema proporcional corregido en los demás. En los municipios de menos de 5000 se cuestionan las listas cerradas pues el alto grado de conocimiento personal entre candidatos y electores debería permitir otras opciones como ha señalado Cosculluela Montaner, L. (2011, pp. 1.495-1.562).

20 Como es sabido, los intentos de limitar las competencias municipales que perseguía la reforma local de 2013 han quedado desfigurados por la jurisprudencia constitucional. En consecuencia, nada impide que un municipio con población inferior a 5000 habitantes que cuente con recursos suficientes, ejerza, además de las competencias reconocidas en el artículo 25. 2 de la LBRL, cualquier otra actividad o servicio en beneficio de los vecinos que no afecten a su sostenibilidad financiera ni supongan una duplicidad con los de otra Administración. Así he tenido ocasión de señalarlo en Carbonell Porras, E. (2019, pp. 50-52); y, con anterioridad, en Carbonell Porras, E. (2014, pp. 777-780). También puede verse, entre otros, Presicce, L. (2019, p. 151 y ss.). 
miciliario de agua potable, alcantarillado, acceso a los núcleos de población y pavimentación de las vías públicas. Como es sabido, corresponde a la Provincia asegurar la prestación integral y adecuada de estos servicios, que es uno de sus fines provinciales propios y específicos (art. 31 LBRL), y las Diputaciones provinciales (o entidades equivalentes) son competentes para la asistencia y cooperación jurídica, económica y técnica con los municipios de menor capacidad económica y de gestión (art. 36 LBRL).

También se establecen particularidades para los municipios pequeños en materia de contratación ${ }^{21}$; de empleo público, con las tradicionales agrupaciones para el sostenimiento en común de la Secretaria, o limitando el personal eventual ${ }^{22}$; existe un régimen simplificado de contabilidad ${ }^{23}$; y solo los municipios menores de 5000 habitantes pueden imponer la prestación personal y de transporte para la realización de obras de la competencia municipal ${ }^{24}$. También se prevén especialidades en materias de competencia estatal, como es la seguridad ciudadana y la seguridad vial: inicialmente sólo los municipios con población superior a 5000 habitantes podían crean policías locales ${ }^{25}$, pero, en cumplimiento de las previsiones de la Ley 45/2007, de desarrollo rural sostenible, se admite una asociación para la ejecución de las funciones asignadas a la policía local, que puede constituirse por dos o más municipios limítrofes pertenecientes a la misma Comunidad Autónoma que separadamente no dispongan de los recursos suficientes para la prestación de este servicio ${ }^{26}$.

Además, el artículo 30 de la LBRL remite expresamente a las Leyes sobre régimen local de las Comunidades Autónomas el establecimiento de regímenes especiales para municipios pequeños o de carácter rural, «en el marco de lo establecido en esta Ley». Pero la realidad es que las Comunidades Autónomas han prestado más atención a los municipios de gran población, especialmente a los que son capitales autonómicas, aprobando leyes específicas para ellos, que a los municipios más pequeños ${ }^{27}$. Respecto de estos, a lo sumo se completan las previsiones para los que funcionan en Concejo Abierto (en particular, en Aragón que

21 En los municipios de menos de 5000 habitantes, el Pleno podrá autorizar la redacción y licitación de proyectos independientes relativos a cada una de las partes de una obra cuyo periodo de ejecución exceda al de un presupuesto anual, si pueden ser utilizadas separadamente o ser sustancialmente definidas (Disposición adicional segunda, 3 y Disposición adicional tercera, 7); las competencias podrán ser ejercidas por las centrales de contratación o por las Diputaciones Provinciales (Disposición adicional segunda, 6); la aprobación del gasto podrá ser sustituida por una certificación de existencia de crédito que se expedirá por el Secretario Interventor o, en su caso, por el Interventor de la Corporación (Disposición adicional tercera, 4), todos de la Ley 9/2017, de 8 de noviembre, de Contratos del Sector Público.

22 El Real Decreto 128/2018, de 16 de marzo, por el que se regula el régimen jurídico de los funcionarios de Administración Local con habilitación de carácter nacional, contempla, en su artículo 9, las agrupaciones para el mantenimiento en común del puesto de la Secretaria en los municipios con recursos insuficientes, correspondiendo a las Comunidades Autónomas la regulación y constitución; y, en el artículo 10 la posible exención por la Comunidad Autónoma, previo informe de la Diputación provincial, Cabildo o Consejo Insular a los municipios con población inferior a 500 habitantes y presupuesto inferior a 200000 euros, de la obligación de crear o mantener el puesto de trabajo de Secretaría, en el supuesto de que no fuese posible efectuar una agrupación con otras Entidades Locales para mantener dicho puesto. Corresponde a la Diputación garantizar la prestación de los servicios de secretaría e intervención en los municipios de menos de 1000 habitantes como ahora puntualiza el artículo 36.1.b) LBRL. Además, en los municipios con menos de 2000 está prohibido el personal eventual, y excepcionalmente podrá contarse con un puesto eventual en los de población comprendida entre 2000 y 5000 habitantes siempre que no existan miembros de la Corporación con dedicación exclusiva (art. 104 bis LBRL) y en estos municipios pueden ser dos o tres concejales lo que estén en exclusiva, como se ha visto.

${ }_{23}$ Los municipios cuyo presupuesto no exceda de 300000 euros, así como aquellos cuyo presupuesto supere este importe, pero no exceda de 3000000 euros y cuya población no supere 5000 habitantes tienen un tratamiento contable simplificado que, en aplicación de lo previsto en el artículo 203 del Texto Refundido de la Ley de Haciendas Locales, (adelante, TRLHL) establece el Ministerio de Hacienda. En la actualidad, la Orden HAP/1782/2013, de 20 de septiembre, por la que se aprueba la instrucción del modelo simplificado de contabilidad local y se modifica la instrucción del modelo básico de contabilidad local aprobada por orden EHA/ $4040 / 2004$, de 23 de noviembre.

24 Artículos 128 a 132 del TRLHL.

25 Así lo estableció la Disposición Transitoria cuarta del Texto Refundido de Régimen Local de 1986, que exigía autorización expresa del Ministerio para los de censo inferior a 5000 habitantes.

26 Disposición adicional quinta de la Ley Orgánica de Fuerzas y Cuerpos de Seguridad del Estado que incorporó la Ley Orgánica 16/2007, de 13 de diciembre, complementaria de la Ley para el desarrollo sostenible del medio rural. El acuerdo de colaboración debe contar con la autorización del Ministerio del Interior o, en su caso, de la Comunidad Autónoma de acuerdo con su Estatuto de Autonomía. El régimen de esta asociación se completa con la Orden INT/2944/2010, de 10 de noviembre. Como precisa la STC 178/2019 de 18 diciembre, en relación con la Ley Foral 23/2018, de las policías de Navarra, se trata del ejercicio de la competencia estatal en materia de seguridad pública, y «no cabe otro tipo de asociación de municipios con competencia para la prestación de servicios de policía local que las asociaciones que se formen en aplicación de lo establecido en la Ley Orgánica de fuerzas y cuerpos de seguridad y su normativa de desarrollo, respetando, por tanto, las condiciones fijadas por el Estado respecto a la colaboración intermunicipal en esta materia». Por otra parte, cuando «por insuficiencia de los servicios municipales» los Alcaldes no puedan ejercer la potestad sancionadora por las infracciones a las normas de circulación cometidas en vías urbanas, la competencia se asume por los Jefes Provinciales de Tráfico (art. 84 del Real Decreto Legislativo 6/2015, de 30 de octubre, por el que se aprueba el texto refundido de la Ley sobre Tráfico, Circulación de Vehículos a Motor y Seguridad Vial).

27 Tuve ocasión de ponerlo de manifiesto en Carbonell Porras, E. (2007, pp. 775 y ss.); y en Carbonell Porras, E. (2009). 
ha aprobado la Ley 9/2009, de 22 diciembre), y se prevé la aprobación de un reglamento orgánico tipo de carácter supletorio y de modelos-tipo de actas, ordenanzas y otros documentos municipales ${ }^{28}$. Algunas leyes autonómicas contemplan regímenes específicos para municipios con núcleos de población diferenciados, rurales, o con escasa población, pero no han sido objeto de ulterior desarrollo y, en consecuencia, no se han concretado en qué consisten las especialidades ${ }^{29}$. Probablemente porque la opción preferida por las Comunidades Autónomas ha sido la potenciación de mancomunidades de municipios especialmente pensadas para solventar los problemas de los municipios más pequeños ${ }^{30}$.

De lo anterior pueden extraerse dos conclusiones: la primera, que la organización básica y necesaria para los municipios de menos de 5000 habitantes es mínima, lo que permite amplio margen de regulación al legislador autonómico y al propio municipio. Se produce así una de las mayores paradojas de nuestro Derecho local pues la potestad de autoorganización es considerablemente más amplia en los municipios pequeños que en los municipios considerados de gran población, como en todos los de población superior a los 5000 habitantes. Otra cosa muy distinta es que las Comunidades Autónomas no se hayan mostrado particularmente interesadas en explotar al máximo estas posibilidades, como tampoco han optado decididamente por articular soluciones a los problemas de los municipios más pequeños. La segunda, es que no puede sostenerse, como es habitual en nuestra doctrina, que nuestro régimen local sea homogéneo y no contemple las realidades diversas de nuestros municipios ${ }^{31}$. No es así en el caso de la legislación estatal como ha podido comprobarse, y también podrían aprobarse regulaciones diversas por las Comunidades Autónomas que lo han hecho cuando así lo han querido como con las capitales autonómicas y los municipios de gran población. Otra cuestión es que no hayan prestado la atención que merecerían los municipios más pequeños.

\section{4. ¿UN ESTATUTO BÁSICO PARA LOS MUNICIPIOS DE MENOR POBLACIÓN PARA HACER FRENTE AL PROBLEMA DEMOGRÁFICO?}

El 18 de junio de 2020, en una nota de prensa, la Ministra de Política Territorial anunciaba, además de otras reformas de carácter local, la elaboración de un "Estatuto Básico de los Pequeños Municipios", como una novedad enmarcada en la Estrategia Nacional frente al Reto Democrático, que perseguiría tres objetivos: «fijar la población al territorio, mantener la calidad democrática del municipio, de acuerdo con nuestro Estado democrático, y garantizar las condiciones de vida de los ciudadanos con independencia del territorio en el que residan, con la prestación de unos servicios públicos de calidad. y otras reformas de carácter local». Para alcanzarlos se incorporarían las siguientes medidas: «simplificación orgánica, agilización procedimental, especialidades en el ámbito de la contratación y en la gestión económica-financiera y patrimonial, especialidades en el régimen de los habilitados nacionales y mecanismos de asistencia por parte de las restantes administraciones a los pequeños municipios». En la misma línea se han publicado otras notas de

28 Por ejemplo, la Ley 7/1999, de 9 de abril, de Administración Local de Aragón (art. 58), la Ley 1/1998, de 4 de junio, de Régimen Local de Castilla y León (art. 77), la Ley 6/1988, de 25 de agosto, de Régimen Local de la Región de Murcia (art. 50), o la Ley 2/2003, de 11 marzo, de Administración Local de Madrid (art. 42).

29 Prevén el establecimiento de un régimen especial para los municipios con núcleos de población diferenciada la Ley 7/1999, de 9 de abril, de Administración Local de Aragón (art. 60), la Ley 1/2003, de 3 marzo, de Administración Local de La Rioja (art. 49), o la Ley 3/1991, de 14 de marzo, de Entidades Locales de Castilla-La Mancha (art. 65). Por otra parte, la Ley 5/1997, de 22 de julio, de Administración Local de Galicia (arts. 88 y 199) se refiere a la declaración de municipio rural para aquellos que tenga como actividad económica principal la agricultura, menos de 25000 habitantes y el número de entidades dentro de su término municipal exceda de diez o la densidad de población sea inferior a la media gallega. O, por último, la Ley 8/2010, de 23 de junio, de régimen local de la Comunidad Valenciana, regula la gestión compartida para los municipios con población inferior a 500 habitantes, aunque podrá extenderse a los que cuente con población entre 500 y 1000 habitantes en los que la evolución demográfica sea negativa de forma persistente (art. 45). En todos estos supuestos, el establecimiento del régimen especial requiere la aprobación de un Decreto de los Consejos de Gobierno que concretará las especialidades. Realizada la búsqueda en los respectivos boletines oficiales no he encontrado tales Decretos, y, por tanto, salvo error, las previsiones legales no han sido efectivamente aplicadas.

30 Así la disposición transitoria cuarta de la Ley valenciana 8/2010 dispone que la aplicación del régimen especial de gestión compartida se realizará por el Consell de forma paulatina, valorando la oportunidad de que se constituyan previamente mancomunidades de interés preferente. En este sentido hay que destacar la mancomunidad de interés general rural prevista en la Ley $7 / 2013$, de 27 de septiembre, de Ordenación, Servicios y Gobierno del Territorio de la Comunidad de Castilla y León, Comunidad Autónoma que no prevé la supresión de municipios, sino articular soluciones a la prestación de servicios en los más pequeños desde la organización periférica de la Comunidad Autónoma. Puede verse Bello Paredes, S. A. (2020, p. 120 ss.).

31 Recientemente y en relación con el tema que nos ocupa Velasco Caballero, F. (2020, pp. 29 y 40 ss.). 
prensa gubernamentales ${ }^{32}$. En una de ella, se refiere el informe presentado por el Secretario de Estado de Política Territorial y Función Pública, Francisco Hernández Spínola, en la Comisión Nacional de Administración local el 16 de noviembre de 2020, que concreta se está elaborando un Anteproyecto de Ley del Estatuto Básico de Menor Población, cuya aprobación comportaría la adición de un nuevo título a la LBRL. Según este informe, la reforma tiene una vocación limitada en su alcance en su condición de normativa básica del Estado; sus principios informadores serán «el servicio efectivo a la ciudadanía; simplificación organizativa y procedimental; cogobernanza multinivel; diferenciación (trato diferenciado en el ámbito competencial en favor de estos municipios por exigencias del principio de equidad); y colaboración en la asistencia a estos municipios»; las medidas de actuación, la «revisión periódica de procedimientos para su simplificación y disminución de las cargas burocráticas; refuerzo de la colaboración interadministrativa; y colaboración en la potenciación de la Administración electrónica». También se alude a medidas relativas al empleo local para garantizar el desempeño adecuado de las funciones reservadas a funcionarios con habilitación de carácter nacional, la creación de agrupaciones de municipios para sostener en común puestos o agrupaciones de personal con sede administrativa común, el uso de medios electrónicos y telemáticos, la posibilidad de que las entidades locales puedan encomendar la selección de sus funcionarios propios y la de articular Planes de Empleo para mejorar la eficiencia la garantía del empleo público y de calidad. No obstante, no he podido acceder al indicado Anteproyecto pues ninguna consulta pública se ha abierto al respecto en la página web del Ministerio de acuerdo con los artículos 26, de la Ley del Gobierno, y 133, de la Ley de Procedimiento Administrativo Común ${ }^{33}$. Quizá se ha prescindido de este trámite al entender que se trata de una norma organizativa de la Administración local en aplicación del apartado 4 del indicado artículo 133. O tal vez el tema haya perdido relevancia con el nombramiento de D. Miquel Octavi Iceta i Llorens como Ministro de Política Territorial y Función Pública (Real Decreto 55/2021, de 26 de enero).

Tampoco las iniciativas parlamentarias al respecto aportan indicios del sentido y alcance de la reforma. El 24 de noviembre de 2020, el Grupo Parlamentario Socialista presentó en el Congreso de los Diputados una proposición no de ley instando al Gobierno a iniciar los trámites para la elaboración de un Estatuto Básico del Pequeño Municipio para su debate en la Comisión de Transición Ecológica y Reto Demográfico, que es retirada en diciembre ${ }^{34}$, y sustituida por dos nuevas proposiciones no de ley para ser debatidas en la indicada Comisión pero también en la de Política Territorial y Función Pública ${ }^{35}$. En estas proposiciones se insta al Gobierno a elaborar y aprobar un Estatuto Básico de los Municipios de Menor Población, en colaboración con la FEMP y otros actores implicados, «que contribuya a fijar la población en las áreas menos densamente pobladas del territorio nacional, afiance la calidad democrática de los municipios y garantice la calidad en la prestación de los servicios públicos», y «contenga medidas dirigidas a mejorar la organización y el funcionamiento administrativo, procedimientos de contratación y prestación de servicios por parte de los municipios de menos de 5.000 habitantes».

Con tan escasos datos, con unas declaraciones tan vagas e imprecisas, no es posible adivinar qué cambiaría. No se acierta a comprender cuáles pueden ser las novedades en el régimen jurídico de los municipios más pequeños antes analizadas y menos aún que tengan naturaleza básica y no supongan una intromisión en las competencias de las Comunidades Autónomas para regular los regímenes municipales especiales ${ }^{36}$ : ¿Es posible una mayor simplificación organizativa de la que existe actualmente en los mu-

32 Por ejemplo, el 8 de julio se anuncia a la primera reunión celebrada con representantes de la FEMP para abordar el Estatuto Básico de los Pequeños Municipios bajo la presidencia de la Secretaria General de Coordinación Territorial del Ministerio de Política Territorial y Función Pública, y la Secretaria General del Reto Demográfico del Ministerio para la Transición Ecológica y el Reto Demográfico; y el 23 de julio se refiere noticia sobre la primera Conferencia Sectorial de Reto Demográfico en la que se fija como uno de los principales objetivos la adopción del indicado Estatuto.

33 https://www.mptfp.gob.es/portal/ministerio/participacion_proyectos.html

34 161/0001692, Boletín Oficial de las Cortes Generales, Congreso de los Diputados, serie D, núm. 185, de 24 de noviembre de 2020, p. 40-41. De acuerdo con el Boletín Oficial de las Cortes Generales, Congreso de los Diputados, serie D, núm. 208, de 26 de enero de 2021, p. 21, esta proposición se retiró por escrito de 16 de diciembre de 2020 . El mismo grupo socialista presenta, el 3 de diciembre, una moción en el Senado, para su debate en la Comisión de Entidades Locales con similar finalidad. Con anterioridad se han realizado diversas preguntas parlamentarias sobre los trámites realizados para la elaboración del Estatuto.

35 Ambas presentadas el 16 de diciembre de 2020, calificadas el 13 de enero de 2021 y publicadas en el BOCG. Congreso de los Diputados, serie D, de 22 de enero de 2021, Núm. 207, con referencias 161/001839, la de la Comisión de Política Territorial y Función Pública (pp. 96-97), y 161/001840, la de la Comisión de Transición Ecológica y Reto Demográfico (p. 106-109).

36 Recordemos ahora que la STC $214 / 1989$ pone de relieve que la expresión "en el marco de lo establecido en esta Ley» que emplea el art. 30 LBRL, puede considerarse superflua pues no supone ningún plus sobre el alcance de la competencia estatal ni limita las competencias autonómicas para regular regímenes municipales especiales y que una «la lectura del precepto permite comprobar el carácter meramente descriptivo y ejemplificativo de los posibles supuestos de municipios susceptibles de ser sometidos, por la Ley au- 
nicipios de población inferior a 5000 habitantes?, ¿qué trato diferenciado en sus competencias merecen estos municipios que, además estaría vinculado con el principio de equidad?, ¿cómo se produciría ese afianzamiento de la calidad democrática que garantizaría la calidad en la prestación de servicios?,¿qué novedad en el régimen jurídico de los municipios pequeños afianzará la población al territorio?, ¿volverán a regularse por el Estado las agrupaciones forzosas para el sostenimiento en común de la secretaría?, ¿Qué modificaciones se piensa introducir en la legislación de contratación del sector público o en la de haciendas locales?,... Poco puede añadirse al respecto, especialmente si tenemos en cuenta que, como vimos, en los documentos relativos al problema demográfico no existe previsión alguna de reforma de la legislación local básica más allá de la necesaria potenciación de los mecanismos de cooperación y asistencia a los municipios más pequeños, además de las acciones a desarrollar en ámbitos de la acción pública de competencia estatal y autonómica.

\section{REFLEXIÓN FINAL}

El análisis demográfico en España parte de la población municipal, pues se fundamenta en los datos que facilita el Padrón Municipal de Habitantes, pero una cosa es que las cifras de vecinos en los diferentes municipios pongan de manifiesto los problemas demográficos en entornos rurales, especialmente la despoblación y el progresivo envejecimiento de las personas que los habitan, y otra muy diferente es que la solución sea una reforma de la LBRL aprobando un estatuto básico para los municipios pequeños. Por lo pronto porque tales problemas no son exclusivos de los municipios más pequeños: las capitales de provincia de la España interior están sufriendo una progresiva pérdida de población y el envejecimiento, como en cualquier sociedad occidental, es un problema generalizado también en el ámbito urbano. Además, nada ha concretado al respecto la legislación vigente sobre desarrollo rural sostenible ni los documentos actuales relativos al reto demográfico. Sin duda la coordinación, la colaboración y la cooperación entre las distintas Administraciones pública es imprescindible para llevar a cabo las diferentes acciones que se proponen para luchar contra la despoblación, y debe potenciarse la necesaria asistencia a los municipios, que son la Administración más cercana a los ciudadanos y, por tanto, la mejor conocedora de los principales problemas de sus vecinos. Lógicamente un municipio, pequeño o no, que cuente con recursos materiales, personales y financieros suficientes podrá adoptar políticas públicas que contribuyan decididamente a su desarrollo socio-económico y, de esta forma, contribuir al mantenimiento de su nivel de población e incluso acometer acciones para recuperarla. Pero de todo esto no cabe deducir que un cambio en el régimen jurídico que rige a los municipios con población inferior a 5000 habitantes afiance la población al territorio como se proclama. De nuevo se confunden los problemas, aunque ahora parece que en un sentido contrario.

El anuncio de este Estatuto, que ha tenido especial repercusión en los medios de comunicación, sobre todo en los de las provincias con mayores problemas demográficos, refleja un cambio en los planteamientos políticos que parece radical: no hace mucho el debate se centraba en la necesidad de suprimir los municipios más pequeños, y ahora parece que se trata de revitalizarlos. Ni una ni otra opción soluciona el problema demográfico, ni las dificultades para que los vecinos que residen en núcleos de población rurales y alejados accedan a unos servicios esenciales a los que, sin duda, tienen derecho ${ }^{37}$. Recordemos ahora que, con ocasión de la crisis económica, se revitalizó el clásico debate sobre nuestra planta municipal, que culminó con una Ley como la LARSAL tan deficiente técnicamente como criticada en todos los foros. Entonces, siguiendo al Profesor Rebollo Puig, señalé que el problema no es el reconocimiento legal de un municipio pequeño, que cuesta poco y no suele endeudarse, sino que existen vecinos. Las personas que residen en dicho municipio, por pocas que sean y por complicado que resulte acceder a dicho pueblo,

\footnotetext{
tonómica, a un régimen especial, sin que suponga ni una constricción al legislador autonómico para establecer tal régimen especial, ni tampoco una limitación a fijarlos, puesto que, por la propia cláusula final con la que se cierra la enumeración, deja un amplísimo margen de discrecionalidad y creatividad a la legislación de la Comunidad Autónoma». Otra cosa es el art. 9 que prohíbe el establecimiento de «regímenes locales de carácter singular, es decir, con aplicación limitada a determinadas y concretas Entidades locales individualizadas por la propia norma», «regímenes, de caso único, singulares o particulares». No obstante, como sabemos, las leyes autonómicas sí han establecido particularidades para determinados municipios en cuando capitales autonómicas (Palma de Mallorca, Pamplona, Santiago de Compostela, Zaragoza, Mérida...).

37 No lo considera así López Ramón, F. (2020, pp. 125-147), que vincula el problema demográfico y la reforma del mapa municipal, con la reestructuración de la planta municipal para el establecimiento de municipios con población mínima de 5000 habitantes, que se acompañaría con una revisión de las competencias y la prestación de servicios (pp. 146).
} 
tienen derecho a la prestación de unos servicios básicos y generales. Por razones obvias el coste de esa prestación será mucho más elevado que el mismo servicio en una gran ciudad, pero habrá que mantenerlo mientras exista población y el hecho de que desaparezca la entidad local no soluciona el problema, ni esta realidad cambia porque se modifiquen las normas que rigen estos pequeños municipios ${ }^{38}$. Y con esto no se defiende el mantenimiento de aquellos municipios que han perdido su sentido institucional, su sustrato social, identidad o realidad.

Ahora parece que han cambiado las tornas y ya no se trata de eliminar los municipios pequeños sino potenciarlos, combatiendo la despoblación en el ámbito rural con políticas que favorezcan que los vecinos permanezcan residiendo en sus municipios e incluso que las personas abandonen las ciudades para regresar a los pueblos. El objetivo es plausible y se ha visto potenciado por la crisis sanitaria pero tampoco queda claro qué hay que cambiar en el régimen jurídico de los municipios con menor población para la consecución de estos fines.

Lo sorprendente es que quienes impulsan la potenciación de los municipios más pequeños no son diferentes de quienes cuestionan su existencia. Aceptar estos municipios con poca población, cuya naturaleza jurídica sería la misma que los principales municipios de nuestro país, hace saltar por los aires una determinada concepción de la autonomía local que ha terminado por imponerse. Una concepción exagerada de la autonomía local que cuestiona la naturaleza administrativa de los Municipios para asimilar su organización al parlamentarismo o al presidencialismo, que persigue equiparar las normas aprobadas por los Plenos a las leyes para que cubran incluso las reservas constitucionales de ley, que pretende atribuirles la mayoría de las competencias, suprimir al mínimo la tutela de las Administraciones superiores... Como ha referido el profesor Rebollo con la agudeza que le caracteriza: "cuando se opta por todo ello y esa especie de omnipotencia municipal, entonces bajar a la realidad de nuestros numerosos y diminutos municipios provoca un shock en el que, entre espasmos, se condena a esos enanos al exterminio como aguafiestas de la orgía municipalista. Pero en todo ello, además del error de base de una autonomía local desorbitada y desbocada, subyace un planteamiento desenfocado: se parte de lo que es la autonomía municipal y, en consecuencia, de lo que debe ser y hacer un municipio -conceptos estos, los de municipio y autonomía, que para estas teorías son previos y están en los cielos del mundo de las ideas-; después se afirma que cualquier pueblo que no sea capaz de hacer eso no debe ser un municipio. Pero es una forma de razonar un poco rara. Por lo menos aceptemos que hay otra forma de plantear la cuestión: se puede partir de que los pueblos, auténtica unidad social de convivencia básica, han de tener una Administración, que es la municipal; y, partiendo de esos pueblos reales, de sus necesidades y de sus posibilidades de autoadministración, se configura a su medida a los municipios y a su autonomía. Porque imagino, parafraseando la afirmación evangélica, que no se hicieron los municipios para la autonomía sino la autonomía para los municipios. Y aun antes cabría decir que no se hicieron los pueblos para los municipios sino los municipios para los pueblos, y todo ello para las personas. Se ha sacralizado al municipio y a su autonomía, y después se sacrifica en holocausto ante su altar a los pueblos incapaces de soportar el papel estelar que se ha decidido que representen. Pero quizá habría que pensar al revés. Es como si hiciéramos un traje grande y fastuoso para todos, critiquemos la existencia de personas menuditas y rústicas a las que les quede mal y los condenemos a la desnudez o a compartirlo con otros hasta conseguir que rellenen esa indumentaria. Lo que hay que hacer es distintos trajes y ayudar a todos -a los que son municipios y, aunque pequeños, merecen seguir siéndolo- a llevarlos con dignidad» ${ }^{39}$. Discúlpenme esta larga cita que, creo, se justifica por su claridad y porque quizá no haya caído en saco roto: tal vez ahora se está rectificando con la intención de hacer ese «traje» que necesitan los municipios más pequeños, aunque hasta el momento no se haya acertado a exponer. ¿O es demasiado optimista pensar así?

38 Rebollo Puig, M. (2008), señala que el problema para conseguir servicios de calidad está en la existencia de pueblos pequeños y alejados de otros y, por eso, no se sabe bien qué se gana negando a esos pequeños pueblos hasta la existencia de una Administración municipal propia (p. 175), que no comporta «que vaya a existir una escuela ni un centro de salud ni una modesta oficina de correos o una estación de autobuses. Los vecinos de ese pueblo, aunque sea municipio, tendrán que ir a la escuela o al instituto de otro pueblo; y, a la inversa, el cartero deberá de llevar allí las cartas o deberá parar allí algún autobús, aunque no sea municipio» (p. 180). También en Rebollo Puig, M. (2012, p. 195 y ss.). En los municipios con población inferior a 1000 habitantes, como se ha visto, ningún cargo podrá estar en dedicación exclusiva y, por tanto, percibir una retribución ni podrán contar con personal eventual. Además, el nivel de endeudamiento de los municipios de menor población es escaso, un $11 \%$ en los de población inferior a 1001 habitantes según el Informe núm. 931, de 25 de junio de 2013, del Tribunal de Cuentas (BOE de 19 de septiembre). Puede verse Carbonell Porras, E. (2013, pp. 39-45).

39 Rebollo Puig, M. (2008, pp. 180-181) 


\section{REFERENCIAS BIBLIOGRÁFICAS}

Bello Paredes, S. A. (2020). Castilla y León vacía (vaciada): esperando a Ulises. Revista de Estudios de la Administración Local y Autonómica. Nueva época, 13, 110-130. https://doi.org/10.24965/reala.i13.10728

Carbonell Porras, E. (2007). Comentario al artículo 30. En M. Rebollo Puig (dir.) y M. Izquierdo Carrasco (coord.), Comentarios a la Ley Reguladora de las Bases de Régimen Local (tomo I), Tirant lo Blanch.

Carbonell Porras, E. (2009). Los municipios de gran población, cinco años después. Revista General de Derecho Administrativo, 20.

Carbonell Porras, E. (2013). La planta local: análisis general y perspectivas de reforma. En J. J. DÍEZ SÁNCHEZ (coord.), La planta del Gobierno Local. Actas del VIII Congreso de la Asociación Española de Profesores de Derecho Administrativo (Alicante, 8 y 9 de febrero de 2013) (pp. 17-59). Fundación Democracia y Gobierno Local.

Carbonell Porras, E. (2014). Sobre la reforma local y las competencias municipales propias. Revista Vasca de Administración Pública, 99/100, 765-781. https://apps.euskadi.eus/t59auUdaWar/R2/verArticulo?numejem=99\&tip $\mathrm{o}=\mathrm{R} \&$ seccion $=38 \&$ correlativo $=1 \&$ contenido $=32 \&$ locale $=$ es

Carbonell Porras, E. (2018). La alteración de términos municipales en la reforma local de 2013: crónica de un fracaso anunciado. Revista de Estudios de la Administración Local y Autonómica. Nueva época, 9, 5-21. https://doi. org/10.24965/reala.v0i9.10513

Carbonell Porras, E. (2019). La reforma local en España: algunas reflexiones cinco años después. En E. Carbonell Porras y G. Piperata (dirs.), La reforma del Gobierno Local en España e Italia. Editoriale Scientífica.

Comisión Europea (17 de junio de 2020). Informe de la Comisión Europea sobre el impacto del cambio demográfico. https://ec.europa.eu/info/sites/info/files/demography_report_2020_n.pdf.

Cosculluela Montaner, L. (1987). El Concejo Abierto. Revista de Estudios de la Administración local y Autonómica, 234, 199-223. https://doi.org/10.24965/reala.vi234.8500

Cosculluela Montaner, L. (2011). Las elecciones locales. En S. Muñoz Machado (dir.), Tratado de Derecho Municipal (vol. II). lustel.

Cosculluela Montaner, L. (2013). Reforma de la Administración Local. Una oportunidad de modificar la planta municipal que no puede perderse. Revista Española de Derecho Administrativo, 157, 11-19.

Cosculluela Montaner, L. (2017). El municipio español del siglo XXI: de nuevo sobre el mapa municipal. En L. Míguez Macho y M. Almeida Cerreda (coords.), Los retos actuales del derecho administrativo en el Estado autonómico: estudios en homenaje al profesor José Luis Carro Fernández-Valmayor, (vol. 1). Escola Galega de Administración Pública, Andavira y Fundación Democracia y Gobierno Local.

Díez Sastre, S. (2019). Las formas de gobierno local tras cuarenta años de Ayuntamientos democráticos: evolución y retos. Documentación Administrativa. Nueva época, 6, 114-128. https://doi.org/10.24965/da.i6.10767

Federación Española de Municipios y Provincias (enero de 2017a). Población y despoblación en España 2016 [documento de trabajo de la Comisión de Despoblación]. http://femp.femp.es/files/566-2117-archivo/20170125\%20 informe_despoblacion.pdf

Federación Española de Municipios y Provincias (abril de 2017b). Listado de medidas para luchar contra la despoblación en España [documento de acción de la Comisión de Despoblación]. http://www.femp.es/sites/ default/files/multimedia/documento_de_accion_comision_de_despoblacion_9-05-17.pdf.

Federación Española de Municipios y Provincias (2019). Los Göbiernos locales contra la despoblación [Declaración del XII Pleno de la FEMP, celebrado en octubre de 2019]. http://www.femp.es/sites/default/files/multimedia/ declaracion_los_gobiernos_locales_contra_la_despoblacion.pdf.

Fernando Pablo, M. M. (dir.), Domínguez Álvarez, J. L. (dir.) y Tomé Domínguez, P. M. ${ }^{a}$ (coord.), (2020). Rural renaissance: Derecho y medio rural. Thomson Reuters Aranzadi.

García-Moreno Rodríguez, F. (dir.) (2019). La despoblación del mundo rural: algunas propuestas (prácticas y realistas) desde los ámbitos jurídico, económico y social para tratar de paliar o revertir tan denostado fenómeno. Thomson Reuters Aranzadi.

González Bustos, M. á. (2020). Mujer y desarrollo sostenible en el medio rural. Atelier.

Grupo Parlamentario Socialista (2020). Moción, de 3 de diciembre de 2020, del Grupo Socialista en el Senado, para instar al Gobierno a elaborar un anteproyecto de Ley mediante el que se apruebe un Estatuto Básico para los Municipios de Menor Población. https://www.senado.es/web/expedientdocblobservlet?legis=14\&id=68278

Instituto Nacional de Estadística (2020). Nota de prensa con el avance de la Estadística del Padrón Continuo a 1 de enero de 2020. https://www.ine.es/dyngs/INEbase/es/operacion.htm?c=Estadistica_C\&cid=1254736177012\&men u=ultiDatos\&idp $=1254734710990$

López Ramón, F. (2020). La lucha contra la despoblación rural. En T. Font i Llovet y A. Galán Galán (dirs.), Anuario del Gobierno Local 2019. Fundación Democracia y Gobierno Local.

Ministerio de Medio Ambiente, y Medio Rural y Marino (2009). Programa de Desarrollo Rural Sostenible para el período 2010-2014. https://www.mapa.gob.es/es/desarrollo-rural/planes-y-estrategias/ley-para-el-desarrollo-sostenible-delmedio-rural/prog-desarrollo-rural-sostenible/ 
Ministerio de Política Territorial y Función Pública (8 de julio de 2020a). Nota de prensa relativa a la primera reunión con la Federación Española de Municipios y Provincias. Recuperado de https://www.mptfp.gob.es/portal/prensa/ actualidad/noticias/ 2020/07/20200708.html

Ministerio de Política Territorial y Función Pública (18 de junio de 2020b). Nota de prensa sobre la reforma local. Recuperado de https://www.mptfp.gob.es/actualidad/noticias/2020/06

Ministerio para la Transición Ecológica y el Reto Demográfico (23 de julio de 2020a). Nota de prensa sobre la primera Conferencia Sectorial de Reto Demográfico. Recuperado de https://www.miteco.gob.es/es/prensa/200723confere nciasectorialretodemografico_tcm30-510784.pdf

Ministerio para la Transición Ecológica y el Reto Demográfico (2020b). El reto demográfico y la despoblación en España en Cifras, 2020. https://www.lamoncloa.gob.es/presidente/actividades/Documents/2020/280220despoblacion-en-cifras.pdf.

Ministerio para la Transición Ecológica y el Reto Demográfico (2021). Plan de recuperación. 130 medidas frente al reto, disponible en demográfico. https://www.miteco.gob.es/es/reto-demografico/temas/medidas-reto-demografico/

Pizarro Nevado, R. (2019). Tratamiento de las pequeñas poblaciones tras la reforma del régimen local de 2013 . En E. Carbonell Porras y G. Piperata (dirs.), La reforma del Gobierno Local en España e Italia. Editoriale Scientífica.

Pizarro Nevado, R. (2017). Entidades y «entes» de ámbito territorial inferior al municipio tras la reforma local de 2013. Revista de Estudios de la Administración Local y Autonómica. Nueva época, 8, 49-73. https://doi.org/10.24965/ reala.v0i8.10437

Pons Portella, M. (2016). La población mínima de los nuevos municipios: estado de la cuestión tras la Ley de Racionalización y Sostenibilidad de la Administración Local. Revista de Estudios de la Administración Local y Autonómica. Nueva Época, 5, 106-119. https://doi.org/10.24965/reala.v0i5.10353

Presidencia del Gobierno (16 de noviembre de 2020). Nota de prensa relativa a la Comisión Nacional de la Administración Local. Recuperado de https://www.lamoncloa.gob.es/ serviciosdeprensa/notasprensa/territorial/ Paginas/2020/161120-entidades-locales.aspx

Presicce, L. (2019). Las competencias municipales propias, tras la reforma local de 2013 y la jurisprudencia constitucional. En E. Carbonell Porras y G. Piperata (dirs.), La reforma del Gobierno Local en España e Italia. Editoriale Scientífica.

Rebollo Puig, M. (2008). La supresión de los pequeños municipios: régimen, alternativas, ventajas e inconvenientes. Revista de Estudios de la Administración Local y Autonómica, 308, 151-205. https://doi.org/10.24965/reala. v0i308.9701

Rebollo Puig, M. (2012). La crisis económica y la oportunidad de reducir el número de municipios. En L. Cosculluela Montaner y L. Medina Alcoz (dirs.) y M. Hernando Rydings (coord.), Crisis Económica y Reforma del Régimen. Civitas.

Rebollo Puig, M. (coord.) (2019). Derecho Administrativo. Tomo I. Conceptos fundamentales, fuentes y organización (4. ${ }^{a}$ edición). Tecnos.

Velasco Caballero, F. (2020). Municipios urbanos versus municipios rurales: homogeneidad y diversidad en el régimen local. En F. Velasco Caballero (dir.), Anuario de Derecho Municipal 2019 (número 13). 